Brit. f. vener. Dis. (1968), 44, 151.

\title{
FATAL REACTION TO PHENYLBUTAZONE IN A PATIENT WITH REITER'S DISEASE*
}

\author{
BY
}

R. D. CATTERALL

The Middlesex Hospital, London, W.I

Phenylbutazone was introduced into therapeutics in 1949: it rapidly became popular, and latterly, in Great Britain alone, general practitioners have been writing between 3 and 4 million prescriptions for it each year; quantities used in hospitals are unknown. Toxic effects include agranulocytosis, reactivation of peptic ulcers, rashes, vomiting, diarrhoea, and jaundice. The Dunlop Committee on the Safety of Drugs has records of thirteen suspected cases of liver damage, including two deaths, associated with the drug and about seventy deaths from bone marrow depression have been reported.

This paper gives details of a fatal case of acute hepatocellular failure occurring in a patient receiving phenylbutazone for the treatment of Reiter's disease.

A 28-year-old Irish stonemason had come to England from Eire in 1961, and had never been outside the British Isles; he drank up to twelve bottles of Guinness at week-ends but took little or no spirits. There was no past history of parenteral injections or of blood transfusions.

In September, 1966, he was admitted to the Middlesex Hospital with a 5-day history of pain and swelling of the fingers, wrists, and feet, and also pain in the lower part of the back; the pains in his joints had become so severe that he had had difficulty in walking. There had been exposure to venereal infection 3 weeks earlier and for 3 days there had been an urethral discharge with dysuria.

Examination He looked ill and had a body temperature of $99 \cdot 2^{\circ} \mathrm{F} .\left(37 \cdot 5^{\circ} \mathrm{C}\right.$.). There was arthritis affecting the metacarpo-phalangeal joints of both hands; both wrists; the metatarso-phalangeal joints of both feet; both ankles; and both shoulders. There was a purulent urethral discharge and a mild balanoposthitis, and on the mucous membranes of the hard and soft palates there were several superficial erosions. There were no ocular lesions and no lesions of the skin.

* Received for publication July 4, 1967.
An early morning urethral smear showed large numbers of polymorphonuclear leucocytes but there were no bacteria and no trichomonads. Urethral culture was sterile. The urine was hazy with many threads in the first glass of the two-glass test and the second glass was normal. The haemoglobin was $15.2 \mathrm{~g} . / 100 \mathrm{ml}$., and the white cell count was $10,800 / \mathrm{c} . \mathrm{mm}$. with a normal differential count. The erythrocyte sedimentation rate was $5 \mathrm{~mm}$. in one hour. The blood Wassermann reaction, and VD Reference Laboratory and Reiter protein complement-fixation tests were all negative and tests for antinuclear factor were also negative. Radiographs of the chest, hands, wrists, ankles, and feet showed no abnormalities.

Treatment $\mathrm{He}$ was treated with rest in bed, tetracycline $250 \mathrm{mg} .6 \mathrm{hrly}$, and phenylbutazone $100 \mathrm{mg}$. twice daily by mouth; 6 days later the joint symptoms had improved, the swellings had nearly disappeared, and there was no objective evidence of urethritis. He was discharged from hospital and asked to rest at home and to continue the tetracycline and phenylbutazone.

Progress 5 days later there was a severe recurrence of the joint pains, most marked in the left hand and left foot. He felt very unwell and said that his pains were worse than when he was in hospital.

He was readmitted to hospital, and examination revealed an ill-looking man with a fever of $99 \cdot 6^{\circ} \mathrm{F}$. $\left(37 \cdot 6^{\circ} \mathrm{C}\right.$.). The physical signs in the joints were almost identical with those at his previous admission except for some periarticular swelling of both knees and tenderness on palpation over both sacro-iliac joints. There was no evidence of conjunctivitis; there was a small quantity of mucopurulent discharge from the urethra. The erythrocyte sedimentation rate was now $38 \mathrm{~mm}$. in one hour. An electrocardiogram was normal.

He was again treated with rest in bed, tetracycline $250 \mathrm{mg}$. $6 \mathrm{hrly}$, and phenylbutazone $200 \mathrm{mg}$. twice daily. The arthritis improved but the erythrocyte sedimentation rate continued to rise and on October 17, 1966, was $60 \mathrm{~mm}$. in one hour. On October 28 he developed an 
erythematous, macular rash involving the whole of the skin; additionally there was some cutaneous oedema and there were several petechiae around the ankles. His temperature was now rising to $103^{\circ} \mathrm{F}$. $\left(39.5^{\circ} \mathrm{C}\right.$.) on occasions. A few discrete, non-tender lymphatic nodes were palpable in both groins and in the neck. The rash was thought to be due to phenylbutazone and this was discontinued as was the tetracycline. At this stage the erythrocyte sedimentation rate was $42 \mathrm{~mm}$. in one hour, and the white cell count was $6,200 / \mathrm{c} . \mathrm{mm}$. with 7 per cent. eosinophils. No lupus erythematosus (L.E.) cells were found in the peripheral blood. A midstream specimen of urine was sterile.

The rash worsened and there was marked dequamation and severe pruritus. During the next 24 hours he started to vomit; 2 days later there was deterioration in his general condition and he was noticed to be jaundiced. His liver was now palpable $6 \mathrm{~cm}$. below the costal margin; the spleen was not palpable but there was widespread lymphadenopathy. The urinary output was poor. The eosinophil count rose to 17 per cent.; the serum bilirubin was $7.8 \mathrm{mg}$. per cent.; the direct Van den Bergh test was positive; the serum transaminases were very high, the S.G.O.T. being 1,760 units and the S.G.P.T. 2,400 units, and the alkaline phosphatase was 29 King-Armstrong units. The prothrombin time was 57 seconds and the blood sugar $63 \mathrm{mg}$. per cent.

Termination Within 24 hours he became drowsy and disorientated and developed a flapping tremor of the hands. He was now very deeply jaundiced. He was thought to have acute hepatocellular failure and was started on a regime of glucose fluids, purgation, and neomycin by mouth. The prothrombin time had risen to 180 seconds and he was now bleeding from the mouth, had bloodstained vomit, and occult blood in the faeces. Because of continued deterioration in his condition an exchange transfusion was carried out and he was also given high doses of corticosteroids. He received 10 pints of fresh blood, radioactive chromium studies suggesting that about 80 per cent. of his blood volume had been exchanged. After the transfusion there was a fall in the plasma ammonia level from 234 to $201 \mu \mathrm{g}$. per cent. (normal $50 \mu \mathrm{g}$. per cent.) and there was a transitory improvement in his level of consciousness, but about 24 hours later there was a further rapid deterioration in his condition and he died on November 15, 1966, 16 days after the onset of the rash and 5 days after the appearance of the jaundice. The duration of the illness from the onset of the first joint symptom to death was $7 \frac{1}{2}$ weeks.

\section{Autopsy (Dr D. St.J. Brew)}

The liver was shrunken and soft, weighing only 750 grammes, with a pale, mottled pattern. Microscopically there was destruction of the liver parenchyma in all zones of the lobule with complete loss of normal pattern of liver cords and sinusoids. Only a very few recognizable liver cells remained, adjacent to the portal tracts (Figs 1 and 2). This represented the picture of acute massive necrosis of the liver.
The kidneys showed evidence of acute necrosis of the proximal convuluted tubules (Fig. 3). The urethra appeared normal to the naked eye but microscopically there was patchy infiltration of the submucosa by chronic inflammatory cells with lymphocytes and plasma cells predominating (Figs 4 and 5).

The prostate was normal macroscopically but on microscopic examination in one area there were three small abscesses with necrotic centres and a peripheral zone of histiocytes and lymphocytes (Fig. 6).

The second metatarso-phalangeal joint of the left foot showed fibrinous exudate on the surface of the synovial membrane, and abnormal vascularization of the synovium with infiltration by lymphocytes and plasma cells (Fig. 7).

An interphalangeal joint showed similar changes and at the edge of one articular surface there was a small area showing what appeared to be the beginning of pannus formation (Fig. 8).

The cause of death was considered to be acute massive necrosis of the liver probably due to phenylbutazone. The histological changes in the urethra, prostate, and small joints of the feet were compatible with a diagnosis of Reiter's disease.

\section{Discussion}

The incidence of phenylbutazone jaundice has been stated to be less than 1 per 1,000 patients taking the drug. In the world literature between 1954 and 1966 there were 35 reported cases with nine fatalities; in all but one case the daily dose had been at least $600 \mathrm{mg}$.

There are two principal histological types of phenylbutazone hepatitis. Hepatocellular damage is the more serious and has been found in the majority

Fig. 1.-Section of liver, showing normal pattern of lobules completely lost with gross destruction of the liver parenchyma in all zones.

FIG. 2.-High-power view of section of liver, showing structure of liver cords and sinusoids completely destroyed.

FIG. 3.-Section of kidney, showing acute tubular necrosis of proximal convuluted tubules.

Fig. 4.- Section of urethra, showing subepithelial infiltration with lymphocytes and plasma cells.

FIG. 5.-High-power view of section of urethra, showing subepithelial patchy infiltration with lymphocytes and plasma cells.

FIG. 6.-Section of prostate, showing prostatic abscess with necrotic material in the centre and an inflammatory area of histiocytes and lymphocytes surrounding it.

Fig. 7.-Section of second metatarso-phalangeal joint of left foot, showing fibrinous exudate on surface synovial membrane, abnormal vascularization of the synovium, and infiltration with lymphocytes and plasma cells.

FIG. 8.-Section of an inter-phalangeal joint of toe of left foot, showing early pannus formation, and marked vascularization of the synovial membrane and infiltration with lymphocytes and plasma cells. 
(1)

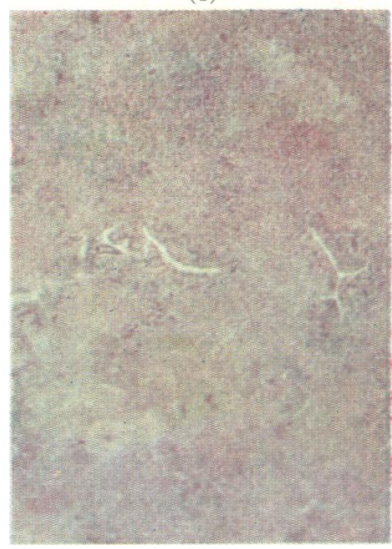

(4)

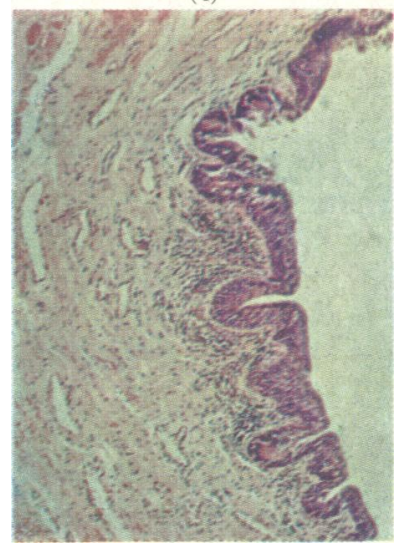

(7)

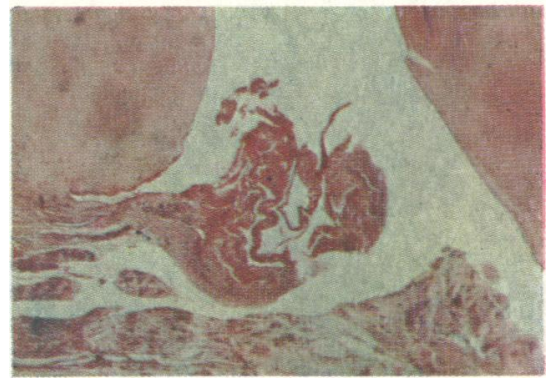

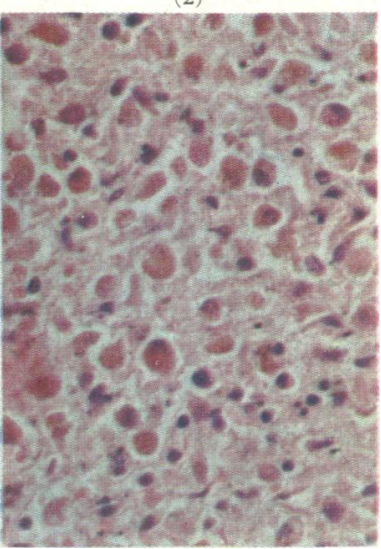

(5)
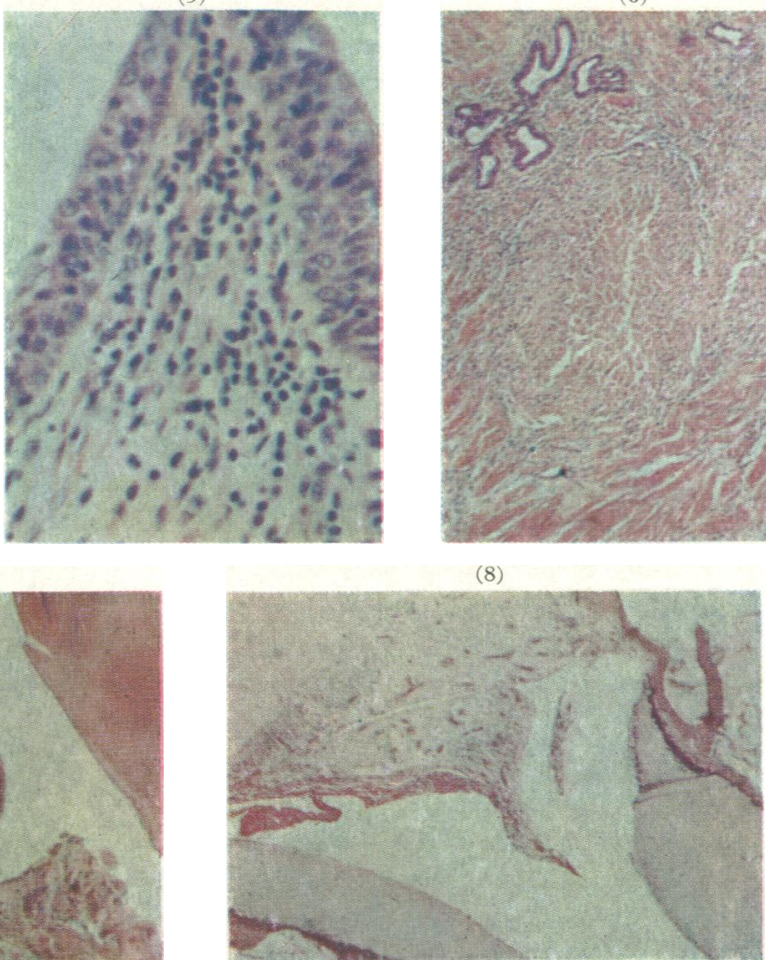

(6)

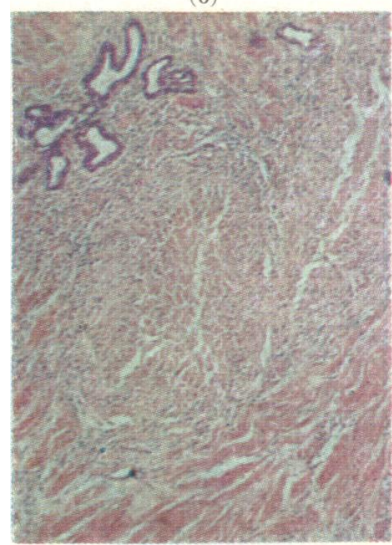

(8)

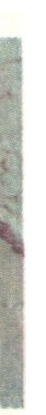

Facing p. 152 
of fatal cases. The onset is usually with malaise, with or without fever. Many patients have a rash, nausea, and vomiting. Jaundice usually appears within 14 days of the onset of the symptoms. Most of the published cases of this type have been fatal within weeks or months of the onset of symptoms.

The second histological type shows evidence of intrahepatic biliary cholestasis. In the majority of cases the jaundice disappears rapidly when the drug is withdrawn and recovery is usual.

Our patient showed clinical and biochemical evidence of acute hepatocellular failure and autopsy revealed evidence of acute massive necrosis of the liver. Although it was impossible to exclude completely an acute fulminating viral hepatitis as the cause of death, there was no positive evidence to support this hypothesis and the most likely explanation is a fatal reaction to phenylbutazone.

\section{Summary}

The case history and clinical details of a patient with Reiter's disease, who developed fatal, acute, hepatocellular failure whilst under treatment with phenylbutazone, are described. Post mortem examination confirmed the diagnosis of acute massive necrosis of the liver, and there was also evidence of acute renal tubular necrosis. Microscopical examination of sections of the urethra, the prostate, and the small joints of the feet showed histological changes compatible with the diagnosis of Reiter's disease.

I should like to thank Dr R. R. Homburg and Dr J. G. Walker for help in the management of the patient and Dr D. St.J. Brew for performing the autopsy and examining the sections.

Une issue fatale due à la phénylbutazone donnée à un malade atteint de la maladie de Reiter. RÉSUMÉ

L'historique d'un cas et les détails cliniques d'un malade atteint de la maladie de Reiter qui a développé une insuffisance hépato-cellulaire aiguë et fatale pendant qu'il était sous traitement avec de la phénylbutazone sont décrits. L'examen post mortem a confirmé le diagnostic d'une nécrose massive aiguë du foie et aussi la présence d'une nécrose tubulaire aiguë des reins. L'examen microscopique des sections de l'urètre, de la prostate et des petites articulations du pied a montré des changements histologiques s'accordant avec le diagnostic de la maladie de Reiter. 